\section{A reforma psiquiátrica e a constituição de práticas substitutivas em saúde mental: uma leitura institucional sobre a experiência de um núcleo de atenção psicossocial}

\author{
Psychiatric reform and substitutive mental health \\ practices: an institutional reading of an experience \\ at a psychosocial care center
}

\author{
${ }^{1}$ Universidade São Francisco, \\ São Paulo, Brasil. \\ 2 Instituto de Psicologia \\ Universidade de São Paulo, \\ São Paulo, Brasil. \\ Correspondência \\ M. Y. Koda \\ Universidade São Francisco. \\ Rua Alexandre Rodrigues \\ Barbosa 45, Itatiba, SP \\ 13251-040, Brasil. \\ mkoda@usp.br
}

\begin{abstract}
This article discusses the development of mental health care services based on the Anti-Asylum Movement. Drawing on contributions from psychoanalysis and social psychology, the study analyzes the conflicts and dilemmas arising in a Psychosocial Care Center (NAPS) in Santos, São Paulo, Brazil. This study is part of Master's degree research at the Social and Occupational Psychology Department, Institute of Psychology, University of São Paulo. Semi-structured interviews were used with workers at the NAPS. According to the interviews, the transformation of the mental health care model mobilizes psychological issues among the workers. Various conflicts and anxieties were observed in relation to changes in the institutional support provided by the NAPS over time. The article analyzes difficulties in dealing with differences in the team or feelings of abandonment resulting from changes in the local administration in the interface between subjects and the institution.
\end{abstract}

Mental Health; Mental Health Services; Health Care Reform; Psychoanalysis; Social Psychology
Mirna Yamazato Koda 1,2

Maria Inês Assumpção Fernandes 2

\section{Introdução}

O processo de transformação das práticas no âmbito da saúde mental, assim como a efetivação dos pressupostos do Movimento de Luta Antimanicomial implicam mudanças em diversos âmbitos: do teórico ao cultural, passando pelo campo de construção de políticas e modelos de atenção. Busca-se não só constituir novas práticas no campo da assistência à saúde mental como também produzir transformações no que diz respeito ao lugar social dado à loucura, ao diferente, questionando uma cultura que estigmatiza e marginaliza determinados grupos sociais.

Tal proposta acaba por colocar em questão valores e representações sobre a loucura há muito arraigados em nossa sociedade e que estão na base de nossa constituição como sujeitos.

Segundo Bleger 1, a sociedade tende a manter uma clivagem entre aquilo que é considerado normal e patológico, colocando à margem loucos, delinqüentes, prostitutas, desviantes em geral das condutas socialmente aceitas. O estigma recai sobre essas figuras portadoras da desrazão, da criminalidade e de uma sexualidade descontrolada. Desse modo, a sociedade acaba por se defender “de sua própria loucura, sua própria delinqüência e sua própria prostituição, e desta maneira aliena, desconhece e trata como se fossem alheias e não lhe correspondessem" 1 (p. 50).

Reincorporar a figura do "louco" ao convívio social implica suspender essa clivagem mobi- 
lizando as mais diversas fantasias e angústias, tendo em vista que a organização de nossa sociedade e cultura desempenha a função de um metaquadro tanto para as instituições quanto para os sujeitos que aí se inserem ${ }^{2}$. Desse modo, a reaproximação dos campos da loucura mobiliza também aspectos de ordem psíquica, o medo frente ao diferente, àquilo que por longos anos ficou depositado e recluso no interior dos muros do hospital psiquiátrico.

Alguns autores 3,4,5,6 têm investigado a construção da rede de serviços substitutivos ao manicômio, valendo-se de um referencial da psicologia institucional e psicanálise de grupos. Tais pesquisas analisam os conflitos e contradições que muitas vezes se instauram a partir da implantação dos serviços substitutivos ao modelo manicomial.

Ao se transformar antigos códigos de relação entre normalidade e loucura, entre técnico e paciente, ameaça-se a segurança do próprio sujeito implicado nessa mudança. Desorganizam-se, aí, as defesas psíquicas socialmente organizadas entre as pessoas 3,4 .

Segundo Kaës 7, nesse momento os antigos apoios não dão mais conta daquilo que é vivido, disparando sentimentos de ruptura psíquica e de ameaça à integridade do ego, sendo necessárias novas formas de regulações. O processo de constituição de novas práticas coloca os trabalhadores diretamente em contato com o novo e o desconhecido, gerando sentimentos de angústia.

O trabalhador sofre uma experiência de desenraizamento ao ver sua própria identidade profissional ser colocada em questão. Entrar num contato mais próximo com o paciente, construir um trabalho mais articulado com profissionais de outras áreas, tendo que ressignificar o seu próprio saber, rompe com uma prática tradicionalmente instituída e reproduzida nos cursos de formação. As referências identificatórias e as identificações do sujeito são questionadas. As representações identitárias que poderiam dar um parâmetro de atuação ao profissional se encontram em um processo de transformação constante.

O presente trabalho se propõe à analise dos conflitos e dilemas vividos em uma instituição de tratamento fundada em pressupostos antimanicomiais. Este trabalho é um desdobramento de pesquisa de mestrado ${ }^{8}$, que se deu entre 1998 e 2002, no Departamento de Psicologia Social e do Trabalho, Instituto de Psicologia, Universidade de São Paulo, orientada pela professora Dra. Maria Inês Assumpção Fernandes.

\section{Método}

Realizamos a pesquisa em um núcleo de atenção psicossocial (NAPS) na cidade de Santos, Estado de São Paulo, Brasil. O trabalho aqui apresentado baseou-se no referencial teórico da psicologia institucional e psicanálise de grupos, e foi desenvolvido por intermédio da análise de entrevistas semi-estruturadas realizadas com nove trabalhadores do serviço (técnicos e funcionários de nível médio).

Pela narrativa desses sujeitos, pudemos apreender não só as questões enfrentadas no cotidiano de trabalho como também os diversos momentos da história desse NAPS, que acabam por revelar algumas questões vividas no processo de desenvolvimento de uma proposta antimanicomial.

Todos os sujeitos entrevistados assinaram Termo de Consentimento Informado. Os nomes dos participantes foram mudados na análise apresentada neste artigo.

\section{O processo de reforma psiquiátrica em Santos}

O Município de Santos foi um dos primeiros locais no Brasil a iniciar um processo de substituição do manicômio por uma rede de serviços territoriais (final da década de 80). Essa transformação se inicia com a intervenção do poder público municipal no hospital psiquiátrico local, a Casa de Saúde Anchieta, denunciado por várias mortes e maus tratos aos pacientes.

No intuito de montar os serviços territoriais (NAPS), o hospital foi dividido em cinco miniequipes, cada uma responsável por uma determinada região de Santos. As equipes organizaram-se a fim de construir os NAPS e realizar a desativação da Casa de Saúde Anchieta 9.

O primeiro NAPS foi inaugurado em setembro de 1989, na zona noroeste de Santos. Pouco tempo depois foram inaugurados outros quatro serviços. Em junho de 1994, ocorreu o fechamento definitivo da Casa de Saúde Anchieta. Tal período é caracterizado por uma grande mobilização política por parte dos trabalhadores de saúde mental do município. A questão da cidadania das pessoas portadoras de transtorno mental ganha espaço, ampliando as discussões para além do campo teórico-técnico.

O trabalho dos NAPS não se dá apenas no período de crise. É, sobretudo, fora desses momentos que a intervenção se faz necessária, no sentido de auxiliar o usuário na construção de seus projetos de vida, aumentando sua autonomia, contratualidade social e qualidade de vida. 
Embora cuidem da doença, os serviços devem procurar valorizar os potenciais de cada pessoa. Segundo Nicácio 10 (p. 91): "Os NAPS não são estruturas simplificadas como as instituições totais; são centros de atenção, de encontro, de produção de sociabilidade, de comunicação, de convivência, de referência cultural".

O NAPS investigado é um dos cinco serviços de cuidados diários implementados no município durante no período de 1989 a 1992. A equipe é composta por: psicólogos, terapeutas ocupacionais, assistentes sociais, médicos psiquiatras, acompanhante terapêutico, enfermeiro e auxiliares de enfermagem.

Os usuários recebem atenção em parte do dia ou durante o dia inteiro, inclusive à noite. Estabelece-se um contrato de atendimento, discutido entre o profissional do NAPS, o usuário e seu familiar. Tal contrato é reajustado sempre que necessário, adequando-se à situação de cada pessoa e particularidades de seu percurso. Há também aqueles que freqüentam atendimento ambulatorial, utilizando-se do serviço mais esporadicamente.

\section{Análise}

Segundo Enriquez 11, as instituições configuramse como elementos de regulação social global, apresentando-se como conjuntos culturais, simbólicos e imaginários. Desse modo, elas oferecem uma cultura, isto é, um sistema de valores, normas, pensamentos que modelam as ações de seus agentes. Elas fornecem uma estrutura de referência não só para aqueles que nela se inserem como para a própria sociedade. Ao se investigar a ruptura com um modelo manicomial, deve-se considerar os efeitos sobre essa regulação social mais ampla, tendo em vista que a existência dos manicômios garantiu não só uma resposta à loucura pautada no paradigma médico-científico, como também garantiu uma forma de discriminação e cisão entre loucos e normais, entre sãos e doentes mentais.

O Movimento de Luta Antimanicomial instaura um processo de transformação não só nas práticas ligadas à saúde mental, como também carrega em si um potencial disruptivo dentro de nossa própria sociedade ao colocar em questão a divisão entre normal e patológico, loucura e normalidade.

Segundo Kaës 2, a instituição não é apenas uma formação social e cultural complexa, ela realiza funções psíquicas múltiplas para os indivíduos na sua estrutura, na sua dinâmica e na sua economia pessoal. "Ela mobiliza investimentose representações que contribuem para a regulação endopsíquica e que asseguram as bases da identificação do sujeito com o conjunto social" 2 (p. 8).

Enriquez ${ }^{11}$ descreve a instituição como um sistema imaginário que capta os indivíduos em seus próprios desejos de afirmação narcísica e de identificação, na sua necessidade de amor e fantasias de onipotência. Desse modo, a instituição funciona como um apoio psíquico ao sujeito que aí se insere, ela delimita o núcleo básico de sua identidade por meio dos grupos. Nesse sentido, podemos dizer que parte do psiquismo do sujeito é grupal e institucional.

Nas entrevistas realizadas no NAPS, era recorrente a referência por parte dos trabalhadores mais antigos sobre o momento de constituição do serviço. Este era tomado como um período épico/heróico de fundação da instituição, de oposição veemente ao modelo manicomial e instauração de um novo modo de se lidar com a loucura.

Conforme mencionado acima, as instituições se constituem também como sistemas simbólicos, elas se colocam como objetos ideais a serem interiorizados por seus agentes. Segundo Enriquez 11 (p. 57), uma instituição "não pode viver sem elaborar um ou mais mitos unificadores (...) sem contar elou inventar uma história que permanecerá na memória coletiva: mitos, ritos, heróis, sagas, cuja função é sedimentar a ação dos membros da instituição, servir-lhes de sistema de legitimação e dar, assim, sentido às suas práticas e às suas vidas. (...) Ela apresenta exigências e obriga a todos a se moverem pelo orgulho do trabalho a realizar: verdadeira missão de vocação salvadora".

Nesse sentido, os momentos iniciais do NAPS se configuram como esse momento heróico de radical contraposição ao manicômio. Conforme mencionado anteriormente, há de se considerar que a cidade de Santos foi uma das pioneiras na construção de uma rede de serviços substitutivos ao manicômio, tendo, na época, um forte respaldo da administração municipal para o fechamento do hospital psiquiátrico local e implementação das novas práticas.

Assim, temos na fala das entrevistadas, sobre o início do trabalho do NAPS: "Para mim era minha primeira experiência na saúde mental, há 12 anos atrás. A gente era bastante jovem. Mas era um projeto muito apaixonante, era um desafio muito grande (...), para a cidade era uma coisa muito nova, esse gosto de desafio (...) Foi uma experiência muito rica, (...) de muito aprendizado. Aprendizado tanto profissionalmente como pessoalmente. Em termos das relações, em termos do que é o humano, em termos dos direitos, da discussão de cidadania, da discussão sobre ética" (Sandra-técnica). 
"Primeiro eu acho que nós tínhamos um ideal de romper mesmo com aquele modelo, que era o manicômio, que era a institucionalização. Nossa! Era um ideal a qualquer preço. E nós não sabíamos também, era tudo muito novo, muito difícil, mas muito belo também porque nós tínhamos muita vontade, muita disponibilidade" (Cláudia - técnica).

Nesse período há uma forte ênfase no discurso político, o lugar de técnico se confundia com o lugar de militante do movimento. Os pressupostos do movimento antimanicomial servem como um sistema de referência para o grupo, de tal modo que tudo que pudesse colocá-lo em questão é rechaçado. É necessário apagar todas as marcas que pudessem lembrar a instituição manicômio.

Um episódio ocorrido nessa época é bastante ilustrativo desse momento do grupo. Numa distração da equipe, uma usuária sai do NAPS e vai até a praia. Lá, ela é socorrida por um bombeiro. O caso gera intensas repercussões na equipe. Surge a idéia de se colocar uma porta para separar os quartos onde os usuários em situação mais aguda pudessem permanecer. Tal idéia é tomada, por parte da equipe, como um ataque frontal ao projeto antimanicomial. Na fala de uma das entrevistadas: "Tinha um grupo do qual eu fazia parte, que achava que não podia isso, que a porta tinha um valor simbólico. A gente tinha acabado com a idéia da porta, não podia ter uma porta que fechasse (...) e aí uma parte da equipe enlouqueceu. A gente achava que era um absurdo isso, que era um retrocesso, que a gente tinha avançado a ponto de não precisar da porta" (Sandra - técnica).

Nesse momento, a coesão grupal se esfacela, parte dos trabalhadores ameaça sair da instituição. Por fim, a porta é colocada, contudo ninguém consegue sustentar o ato de fechá-la. Se a porta simboliza o aprisionamento vivido no manicômio, ela também corresponde a uma forma de proteção, de divisão e discriminação. Para além da memória do hospital psiquiátrico, o grupo não pode suportar as diferenças dentro da equipe.

Temos aquilo que Kaës 12 denomina como momento ideológico do grupo, sua tendência à isomorfia. A indiscriminação e a homogeneidade de pensamento são marcas desse momento. O discurso antimanicomial garante a identidade do grupo.

Segundo Kaës 12, a ideologia, assim como o mito, cumpre uma função de manutenção do contrato narcísico do grupo. A mentalidade ideológica cumpre uma dupla função de ataque e de defesa. O duro embate contra um modelo manicomial hegemônico gera o agarramento a uma mentalidade ideológica como modo de garantir a segurança do sujeito e seu grupo.

A ideologia sustenta e transmite a razão de ser do conjunto, dando um lugar para cada sujeito no grupo, formulando um sistema de representações. Desse modo, o grupo e seus enunciados dão as condições necessárias para a constituição de um sujeito do discurso.

Se por um lado, os grupos são organizados positivamente sobre identificações comuns, comunidades de ideais e crenças, por outro, ele também se organiza negativamente sobre um conjunto de renúncias e recalcamentos. Esse pólo negativo é configurado com base nas alianças inconscientes, que: "situam-se nos pontos de enlace das relações recalcadas mantidas pelos sujeitos singulares e pelos conjuntos de que são parte interessada e parte constituinte. (...) As alianças inconscientes são formações da aparelhagem psíquica dos sujeitos de um conjunto intersubjetivo: casal, grupo, família, instituição. Elas determinam as modalidades do vínculo entre os sujeitos e o espaço psíquico" 12 (p. 269).

$\mathrm{O}$ pacto denegativo se constitui como uma das modalidades de alianças inconscientes. Segundo Kaës 12 (p. 264), tal pacto seria: “aquilo que se impõe em todo vínculo intersubjetivo para ser consagrado, em cada sujeito do vínculo, aos destinos do recalcamento ou da denegação, da negação, da desaprovação, da rejeição ou do enquistamento no espaço interno de um sujeito ou de vários sujeitos".

Tal pacto se dá a fim de que o vínculo no grupo se organize e se mantenha, assegurando a continuidade de investimentos dos sujeitos e seus benefícios. Desse modo, o pacto denegativo tem uma função organizadora dos laços do conjunto e também de defesa contra angústias primárias. O descobrimento ou desagregação desses pactos no grupo geram efeitos violentos para os sujeitos aí inseridos.

No grupo em questão, nega-se a herança manicomial e suas relações de violência. O superinvestimento narcísico do grupo, surge como saída para superar antigas tradições, chegando a muitas vezes negar os limites do tratar dentro do modelo antimanicomial. As diferenças entre os profissionais são acobertadas pelo estatuto de militantes de uma causa comum.

A falha do atendimento gera uma ruptura do pacto e instala um processo de crise, ocasionando a desorganização da equipe e fantasias de destruição do grupo.

Outro momento de crise vivida pelos trabalhadores do NAPS se dá por ocasião da mudança de gestão municipal, no final da década de 90. A falta de respaldo da administração para os serviços gera um empobrecimento das práticas. A 
desarticulação da rede, a falta de investimentos e de infra-estrutura limita o campo de ações possíveis. Vemos a desmobilização da equipe e dos projetos que, ao invés de se dirigirem ao território, refluem para dentro da instituição, reforçando o modelo médico/ambulatorial tão criticado anteriormente.

O desânimo dos trabalhadores ganha ares de luto pela perda de algo muito importante para a continuidade de uma proposta antimanicomial: o respaldo da administração política.

“A gente estava assim, era o último suspiro. Se você chegasse aqui há uns dois meses (...) era um clima doente, de depressão. Às vezes, você chegava e ficava ali, na sala aqui em baixo, não fazia nada! Não que você não quisesse, parece que não surgia nada, não pintava nada. Quando estava alguém muito mal, em crise, resgatava um pouco aquela coisa, temos que cuidar, todo mundo se juntava, cuidava daquela pessoa. Saía essa pessoa do surto, todo mundo voltava para aquele estado crônico" (Sandra - técnica).

Desta vez, na fala dos entrevistados, ao papel de técnico ou militante se sobrepõe o de funcionário público em uma conotação pejorativa. É recorrente neste momento uma certa nostalgia com relação ao passado do NAPS. Termos como "antes e depois", "antigamente e hoje em dia", são freqüentes nas entrevistas. Novas rupturas dos contratos narcísicos do grupo se instalam, levando o grupo a se apegar a seus mitos de origem.

Encontramos em tal contexto, com a perda da segurança que o ambiente oferecia, uma limitação dos espaços transicionais e uma redução da capacidade criadora. As funções intermediárias do grupo não conseguem dar conta da crise que se instaura com a mudança de gestão. Segundo Kaës 13 (p. 26), a crise é vivida essencialmente como uma "ruptura da relação inter e intra-subjetiva, no jogo das dependências dos grupos e sociedades". Tal ruptura mobiliza angústias catastróficas, ameaçando a integridade egóica do sujeito.

Há uma perda do apoio institucional e conseqüente perda do apoio psíquico. $\mathrm{O}$ enquadre grupal já não dá mais conta de suas funções de continência, gerando um sentimento de desorganização e esvaziamento.

Se por um lado há um movimento de apatia e de apego aos mitos de fundação da instituição, por outro, há também um movimento sustentado por parte da equipe de investir no trabalho, buscando incrementar as ações técnicas desenvolvidas pelos profissionais.

"Muitas vezes a gente pergunta: então a gente tem esses pacientes, o que nós podemos fazer com eles, né? Como atender esses pacientes? Aí a equipe fala: 'mas nós não temos carro'. A equipe fala: 'é, mas a rede de saúde mental está precá- ria'. Eu não nego nada disso, eu seria maluco se eu negasse que o programa de saúde mental em Santos passa por um instante de reconstrução, não é? Mas o que eu quero dizer? Que eu acho que o atendimento ao psicótico não passa só pelo fornecimento de alimentação, por dar os passes, ou por encaminhar para um trabalho protegido, acho que o profissional que acompanha o psicótico ele tem uma atuação que vai além disso, que vai por se pensar na clínica da psicose" (Jorge - técnico).

Assim, o discurso clínico que no primeiro período do NAPS era questionado como portador de uma herança manicomial, pode ser revisto e ressignificado dentro das novas práticas. É preciso construir elos de passagem também para o campo dos saberes tradicionalmente ligados à assistência, reabilitando funções intermediárias que se encontravam rompidas, criando espaços transicionais que possam garantir a criação de novos modos de tratamento.

\section{Conclusão}

Desenvolvemos essa análise com o propósito de contribuir com uma compreensão dos efeitos das transformações no âmbito da atenção à saúde mental, no que diz respeito a sua dimensão psíquica, compreendida com base no sistema de apoio representado pelos grupos e pelas instituições.

A mudança de paradigmas com relação ao tratamento no campo da saúde mental, exemplificada aqui pelo NAPS analisado, aponta para processos de crise. Consideramos que a superação desta também abarca aspectos psíquicos em jogo neste momento.

Se a contraposição ao modelo manicomial objetiva transformações da cultura, ela remete também a mudanças com relação às alianças inconscientes, aos contratos narcísicos e investimentos psíquicos que se dão nos grupos protagonistas desse processo. As transformações não se dão apenas na ordem do explícito do discurso e das práticas, mas também atingem o âmbito daquilo que subjaz inconsciente e encoberto nos grupos.

O abandono de antigos códigos norteadores das práticas envolve a transformação dos laços de significação vigentes. Ainda que os códigos anteriores sejam inadequados, eles asseguravam um modelo de condutas e representações comuns no que tange ao lugar do técnico, à relação profissional/paciente, à concepção da doença. A transformação desse modo de regulação provoca um momento de fragilidade que é vivida como uma ameaça contra o próprio sujeito e seu grupo 
de pertencimento. Vemos aí uma perda de estabilidade psicológica e social.

Tal análise dá subsídios à compreensão dos processos de crise vividos pelas instituições de tratamento que se desdobram por vezes em ações violentas de cisões da equipe e por outras numa apatia e impotência generalizadas. Pe- lo entendimento de que a instituição e o grupo servem de apoio psíquico aos sujeitos, podemos compreender, mediante um outro ponto de vista, os processos de resistência à mudança e os movimentos ideológicos tantas vezes encontrados em instituições de tratamento.

\section{Resumo}

O presente artigo tem como objetivo desenvolver uma reflexão acerca do processo de constituição dos serviços de atenção em saúde mental pautados pelos pressupostos do Movimento de Luta Antimanicomial. Com base nas contribuições da psicanálise e da psicologia social, desenvolvemos uma análise sobre os conflitos e dilemas vividos em um Núcleo de Atenção Psicossocial (NAPS) localizado no Município de Santos, São Paulo, Brasil. Este trabalho é um desdobramento de pesquisa de mestrado realizada no Departamento de Psicologia Social e do Trabalho, Instituto de Psicologia, Universidade de São Paulo. Utilizamos entrevistas semi-estruturadas realizadas com trabalhadores do NAPS. Pela análise das entrevistas, constatamos que o processo de transformação no modelo de assistência à saúde mental mobiliza aspectos de ordem psíquica no grupo de trabalhadores. Podemos observar uma série de conflitos e angústias ligadas à mudança do apoio institucional representado pelo NAPS ao longo de sua história. A dificuldade de se lidar com as diferenças na equipe ou o desamparo vivido em função de mudanças da administração local são analisados na interface entre sujeito e instituição.

Saúde Mental; Serviços de Saúde Mental; Reforma dos Serviços de Saúde; Psicanálise; Psicologia Social

\section{Colaboradores}

M. Y. Koda colaborou na revisão da literatura, elaboração da metodologia, análise dos resultados e redação do artigo final. M. I. A. Fernandes contribuiu na elaboração da metodologia, análise dos resultados e revisão do artigo final. 


\section{Referências}

1. Bleger J. O grupo como instituição e o grupo nas instituições. In: Kaës R, Bleger J, Enriquez E, Fornari F, Fustier P, Roussillon R, organizadores. A instituição e as instituições: estudos psicanalíticos. São Paulo: Casa do Psicólogo; 1991. p. 41-52.

2. Kaës R, Bleger J, Enriquez E, Fornari F, Fustier P, Roussillon R, organizadores. A instituição e as instituições: estudos psicanalíticos. São Paulo: Casa do Psicólogo; 1991.

3. Scarcelli IR. O Movimento de Luta Antimanicomial e a rede substitutiva em saúde mental: a experiência do município de São Paulo (1989-1992) [Dissertação de Mestrado]. São Paulo: Instituto de Psicologia, Universidade de São Paulo; 1998.

4. Costa ES, Koda MY. Reflexões sobre o trabalho em um hospital dia: as inquietudes da construção de uma prática. In: Vieira MCT, Vicentin MCG, Fernandes MIA, organizadores. Tecendo a rede: trajetórias da saúde mental em São Paulo. Taubaté: Cabral Editora Universitária; 1999. p. 287-95.

5. Weyler AR. Os caminhos das propostas de moradias para ex-pacientes psiquiátricos: as políticas públicas em saúde mental, o morar e a cidade [Dissertação de Mestrado]. São Paulo: Instituto de Psicologia, Universidade de São Paulo; 2004.

6. Fernandes MIA. Saúde mental: a clausura de um conceito. Revista USP 1999; 43:90-9.

7. Kaës R. O intermediário na abordagem psicanalítica da cultura. Psicol USP 2003; 14:15-33.
8. Koda MY. Da negação do manicômio à construção de um modelo substitutivo em saúde mental: o discurso de usuários e trabalhadores de um núcleo de atenção psicossocial [Dissertação de Mestrado]. São Paulo: Instituto de Psicologia, Universidade de São Paulo; 2002.

9. Dos Reis SLC. Da desconstrução do manicômio à construção de um novo modelo de atenção à saúde mental no município de Santos [Dissertação de Mestrado]. São Paulo: Faculdade de Medicina, Universidade de São Paulo; 1998.

10. Nicácio MF. O processo de transformação em saúde mental em Santos: desconstrução de saberes, instituições e cultura [Dissertação de Mestrado]. São Paulo: Pontifícia Universidade Católica; 1994.

11. Enriquez E. O trabalho da morte nas instituições. In: Kaës R, Bleger J, Enriquez E, Fornari F, Fustier P, Roussillon R, organizadores. A instituição e as instituições: estudos psicanalíticos. São Paulo: Casa do Psicólogo; 1991. p. 53-79.

12. Kaës R. O grupo e o sujeito do grupo: elementos para uma teoria psicanalítica do grupo. São Paulo: Casa do Psicólogo; 1997.

13. Kaës R. Introducción al análisis transicional. In: Kaës R, editor. Crisis, ruptura y superación: análisis transicional en psicoanálisis individual y grupal. Buenos Aires: Ediciones Cinco; 1979.

Recebido em 17/Fev/2006

Versão final reapresentada em 24/Nov/2006

Aprovado em 03/Jan/2007 